\title{
Encephalitozoon cuniculi in pet rabbits: diagnosis and optimal management
}

This article was published in the following Dove Press journal:

Veterinary Medicine: Research and Reports

6 November 2014

Number of times this article has been viewed

\author{
La'Toya V Latney' \\ Charles W Bradley ${ }^{2}$ \\ Nicole R Wyre' \\ 'Departments of Clinical Studies, \\ ${ }^{2}$ Departments of Pathobiology, \\ Matthew J Ryan Veterinary Hospital \\ of the University of Pennsylvania, \\ Philadelphia, PA, USA
}

\begin{abstract}
Encephalitozoonosis is a significant microsporidial disease of captive pet rabbits (Oryctolagus cuniculus). This article overviews the life cycle, pathogenesis, and host immune response to the parasite. Clinical presentation, differential diagnoses, antemortem diagnostics, and postmortem diagnosis will be discussed. International seroprevalence data and histologic prevalence estimates in the US are presented. A review of current treatment and control recommendations are discussed based on extensive review of controlled studies, which have found fenbendazole to be effective for limiting spread of the disease.
\end{abstract}

Keywords: Encephalitozoon cuniculi, Oryctolagus cuniculi, microsporidia, encephalitozoonosis

\section{Introduction}

Encephalitozoon cuniculi is a microsporidial parasite that causes renal and central nervous system disease in pet rabbits (Oryctolagus cuniculus). It is a significant disease of captive rabbits and its seroprevalence is internationally recognized. Many clinicians report vestibular disease as one of the most common clinical signs associated with chronic E. cuniculi infection. Although extensive literature review reveals that the lesions caused by E. cuniculi are commonly found histologically in the central nervous system (CNS), these lesions are not consistent with reported clinical signs. The life cycle and pathogenesis of encephalitozoonosis allows E. cuniculi to escape a serologic titer correlation to clinical disease severity, evade humoral-mediated immunity in its rabbit host, remain impervious to therapeutic attempts to reduce sporontmediated inflammation, and escape therapeutic attempts to eliminate germination in chronically infected patients. As E. cuniculi has been implicated as an opportunistic zoonotic agent in immunocompromised humans, ${ }^{1,2}$ it becomes imperative that we recognize its true prevalence in the pet trade. Disease surveillance and reduction of disease transmission is of significant veterinary and public health importance.

Clinical diagnosis of encephalitozoonosis can become difficult for most veterinarians for four major reasons. First, serologic evidence can be used to confirm exposure or infection status, but conventional titers are not correlated with the degree of parasitism and clinical signs. ${ }^{3,4}$ Positive E. cuniculi serology is strong evidence of infection but not necessarily predictive or indicative of clinical signs of disease. Second, seroconversion does not result in a protective response or immunity for the patient. ${ }^{5,6}$ Third, the histologic severity and distribution of lesions associated with E. cuniculi infection are not directly correlated with the severity of neurologic clinical signs or the neuroanatomic localization of antemortem neurologic disease. ${ }^{7-9}$ Finally, current
Correspondence: La'Toya V Latney

Department of Clinical Studies,

Matthew J Ryan Veterinary Hospital of the University of Pennsylvania, 3900 Delancey Street, Philadelphia, PA 19104-6010, USA

$\mathrm{Tel}+\mathrm{I} 2155763497$

Fax + I 2I5 5739457

Email llatney@vet.upenn.edu 
treatment recommendations are limited to a few studies that show efficacy in reducing continued neural migration and spore counts, and despite spore reduction, clinical signs can persist. For seropositive patients who have neurologic clinical signs, they are often associated with the inflammation caused by cell rupture, and therapeutic trials that address $E$. cuniculimediated inflammation are limited. ${ }^{10-12}$ This article attempts to provide an extensive review of the literature that can act as a guide to correlate scientific findings with a clinically relevant approach that aids in diagnosis, treatment, and prevention of encephalitozoonosis in pet rabbits.

\section{Life cycle and pathogenesis}

Among the species in the genus Encephalitozoon of the phylum Microsporidia, E. cuniculi is arguably the most common species in terrestrial animals. There are three major genotypes or strains of E. cuniculi, which include E. cuniculi genotype 1, or the rabbit strain, E. cuniculi genotype 2, or the mouse strain, and E. cuniculi genotype 3, or the dog strain. Genotype 1 or rabbit strain will be discussed, as it is associated with disease in the companion rabbit. Since E. cuniculi was first detected as an infectious agent in rabbits in $1922,{ }^{13}$ the genotype isolated from rabbits in later years was given the designation of genotype I. E. cuniculi was first reported in $1922^{13}$ as a significant cause of neurologic disease in laboratory rabbits. Cox et $\mathrm{al}^{14}$ have since demonstrated the life cycle of this obligate intracellular parasite and its pathogenesis in experimental and naturally infected rabbits. Previously considered as protozoa, microsporidia are actually accepted as fungi. The microsporidia spores retain fungal elements, including fungal proteins such as tubulins, trehalose, and chitin, and are ancestral relatives of zygomycetes. ${ }^{15}$ The ultrastructural anatomy of the spore reveals a nucleus, a polar tube (or filament) that is anchored by an anterior disc, a posterior vacuole that is surrounded by an internal chitinous endospore layer, and an external proteinaceous exospore layer.

$E$. cuniculi has a direct life cycle with both horizontal and vertical (transplacental) transmission. In rabbits, the common routes of natural horizontal infection are via the small intestine (ingestion of urine-contaminated feed) and respiratory tract (inhalation of spores). Experimental routes of transmission also include traumatic transmucosal, intravenous, intrathecal, and rectal infection (see Table 1).

E. cuniculi organisms can enter host cells by two recognized mechanisms; however, E. cuniculi primarily infects host cells through the extrusion of its polar filament and injection of its infectious sporoplasm (genetic machinery and DNA) into a host cell. Cellular phagocytosis of the spore by host cells has also been demonstrated, ${ }^{16,17}$ but this has not been shown to be the primary infectious route in experimental in vitro infection rodent tissue models.

Changes in $\mathrm{pH}$ and osmotic pressure cause the ejection of the polar tube and sporoplasm from the spore with subsequent penetration of the host cell, a process described as germination. ${ }^{18}$ Once the sporoplasm injection into the host cell has occurred, the sporoplasm develops into its proliferative form (known as a meront) and divides via merogeny. The meronts differentiate into sporonts, and subsequently into sporoblasts. Sporoblasts then develop their polar tube, disc, anterior and posterior vacuoles, and plasma membrane, and become mature infective spores. This process occurs within a parasitophorous vacuole in the host cell cytoplasm, and rupture of this vacuole and host cell results in dissemination of infective spores into the host.

Predilection sites for the spores include the brain, kidney, lung, lens, and myocardium. ${ }^{11,14}$ The spores are shed in the urine. Transplacental transmission often leads to intraocular infection in young rabbits. ${ }^{24-27}$ Unilateral phacoclastic uveitis results when spores induce rupture of the lens and lenticular contents are released, causing a granulomatous uveitis. ${ }^{24-27}$ A summary of transmission, organ predilection sites, seroconversion, and excretion timelines in experimental and natural infection models is outlined in Table 1.

\section{Host immunity}

Many studies on the host innate immune response and cellmediated immunity related specifically to E. cuniculi are limited to murine models.

\section{Cell-mediated immunity}

E. cuniculi organisms have evolved to become successful intracellular parasites. These adaptations include the development of the polar tube, and intracytoplasmic vacuole formation, and immunologic-based strategies to evade destruction in the host. Several studies have shown that the host response to disease is primarily cell-mediated..$^{6,14,18}$ In experimental E. cuniculi infection studies in immunodeficient mice, the host's cell-mediated immune response was responsible for limiting lethal E. cuniculi disease and improved host resistance. ${ }^{18} \mathrm{CD} 8+\mathrm{T}$ cells have been shown to be independently successful at preventing lethal E. cuniculi disease in infected immunodeficient mice. Athymic mice die from E. cuniculi infections, but survival can be prolonged in mice that receive adoptive transfer of T-enriched splenic cells, but not in those that receive B-cell-enriched transfers. 
Table I Summary of Encephalitozoon cuniculi infection, organ predilection, seroconversion status, and parasite excretion in experimentally and naturally infected rabbits

\begin{tabular}{|c|c|c|c|c|}
\hline & \multicolumn{2}{|l|}{$\begin{array}{l}\text { Adults } \\
\text { (>6 months of age) }\end{array}$} & \multirow{2}{*}{$\begin{array}{l}\text { Young adult } \\
\text { (12-2 I weeks) } \\
\text { Natural }\end{array}$} & \multirow{2}{*}{$\begin{array}{l}\text { Young } \\
\text { (newborn to } 7 \text { weeks) } \\
\text { Natural }\end{array}$} \\
\hline & Experimental & Natural & & \\
\hline Routes of transmission & $\begin{array}{l}\text { Transmucosal after trauma, } \\
\text { intravenous, intrathecal, } \\
\text { rectal, ingestion }\end{array}$ & $\begin{array}{l}\text { Ingestion, } \\
\text { inhalation }\end{array}$ & Ingestion & Intrauterine \\
\hline Primary predilection site & Kidney & & Kidney & Lens, kidney \\
\hline $\begin{array}{l}\text { Serum antibody } \\
\text { development }\end{array}$ & $2 \mathrm{I}$ days $\mathrm{PE}$ & & |4-2| days PE & $\begin{array}{l}\text { Antibodies developed at } \\
\text { birth } \\
\text { Maternal antibodies } \\
\text { dissipate } 4 \text { weeks after } \\
\text { birth, corresponding with } \\
\text { weaning age }\end{array}$ \\
\hline Urinary excretion & 63 days $P E$ & & 28-42 days PE & Not prior to 48 days PE \\
\hline $\begin{array}{l}\text { Duration of urinary } \\
\text { excretion }\end{array}$ & $\begin{array}{l}|7-3| \text { days PE consistently, } \\
\text { then sporadically for } 90 \text { days }\end{array}$ & & $\begin{array}{l}\text { Consistently up } \\
\text { to } 63 \text { days PE }\end{array}$ & Unknown \\
\hline $\begin{array}{l}\text { Lesions associated } \\
\text { with acute infection }\end{array}$ & $\begin{array}{l}30 \text { days PE: lung, kidney, } \\
\text { and liver }\end{array}$ & & $\begin{array}{l}\text { 14-28 days PE: kidney } \\
\text { 28-42 days PE: kidney }\end{array}$ & $\begin{array}{l}\text { At } 10,22,32 \text {, and } 48 \text { days } \\
\text { PE: no histologic lesions in } \\
\text { lung, kidney, liver, or brain }\end{array}$ \\
\hline $\begin{array}{l}\text { Lesions associated } \\
\text { with chronic infection }\end{array}$ & $\begin{array}{l}98 \text { days PE: heart, brain, } \\
\text { kidney }\end{array}$ & & $\begin{array}{l}\text { 42-63 days PE: kidney, } \\
\text { brain } \\
\text { 70-96 days PE: kidney }\end{array}$ & Possible lenticular changes \\
\hline CNS tropism & 8 weeks PE & & 7-9 weeks PE & Unknown \\
\hline
\end{tabular}

Note: Data from Cox et al ${ }^{14}$; Wasson and Peper ${ }^{16}$; Didier et al ${ }^{18}$; Owen and Gannon ${ }^{19}$; Cox and Gallichio ${ }^{20}$.

Abbreviations: CNS, central nervous system; PE, post-exposure.

\section{Innate immunity}

Macrophages have a complex role in response to E. cuniculi infection. First, macrophages are directed by the cytokinemediated instruction of T-cells to phagocytose infected cells. Interferon gamma (IFN- $\gamma$ ), which is secreted by activated T-cells, has also been shown to mediate macrophage activity

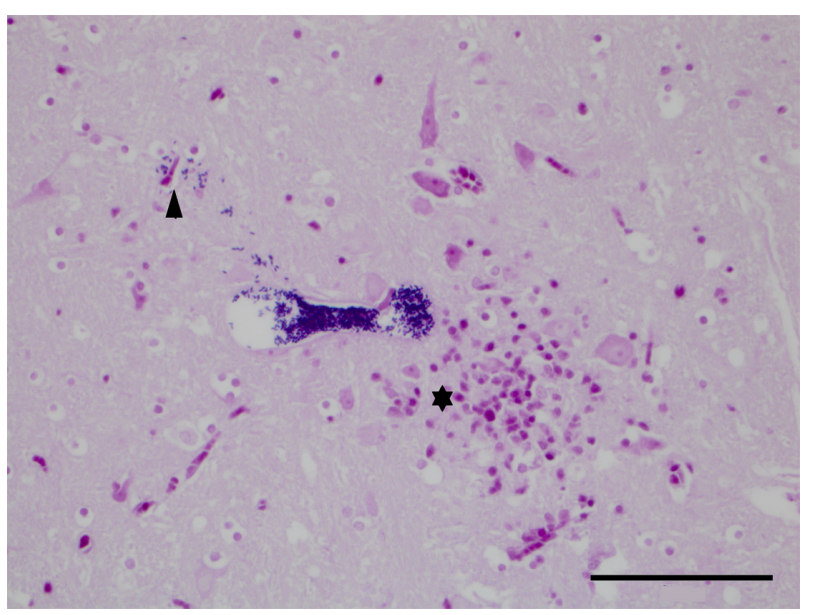

Figure I Brainstem: a parasitophorous vacuole with distinct Gram-positive I.5 $\times 2.5 \mu \mathrm{m}$ spores. A few single Gram-positive spores can be seen escaping from the vacuole into the adjacent neuropil (arrowhead). There are increased numbers of microglial cells and astrocytes (gliosis) and likely a few lymphocytes, all of which stain pink, and a few viable neurons $(\star)$. (Gram's stain, 400× magnification, bar $50 \mu \mathrm{m}$ ). against $E$. cuniculi spores. Murine studies have shown that serum increases in the cytokine in response to E. cuniculi infection. IFN- $\gamma$ knockout mice and mice administered antiIFN- $\gamma$ antibodies succumb to lethal E. cuniculi infections. ${ }^{21}$

Macrophages are also utilized by E. cuniculi to complete its life cycle. Infective spores have been shown to inhibit phagosomal and lysosomal fusion in macrophages. ${ }^{22,23}$ Infected macrophages that have not destroyed the infective spore can migrate into the lymphatic system. Nonprofessional phagocytic cells, including epithelial cells, mesenchymal cells, endothelial and fibroblasts have been shown to engulf and eliminate $E$. cuniculi spores. These nonprofessional phagocytic cells have not been shown to phagocytose the organisms as effectively as professional phagocytic macrophages.

Intraepithelial lymphocytes, largely activated by IFN- $\gamma$ and inhibited by interleukin-10, have been shown to kill E. cuniculi-infected intestinal mucosa after oral transmission. ${ }^{6}$ Natural killer cells have been shown to mediate innate responses through perforin-mediated lysis of infected cells and by secreting IFN- $\gamma$, which modulates the phagocytic activity of macrophages. Dendritic cells may be involved with a protective mechanism after E. cuniculi exposure, because immunosenescence studies in mice reveal that $E$. cuniculi 
reinfection occurs in dendritic cell-deficient mice, and that transfer of sera from young mice exposed to E. cuniculi results in protective immunity. ${ }^{6}$

\section{Humoral immunity}

All immune competent animals exposed to E. cuniculi develop antibodies that may persist for the life of the host; however, they do not offer protection against reinfection. ${ }^{18}$ In humans, rabbits, nonhuman primate and rodent studies of microsporidial infections, it has been shown that humoralmediated responses to E. cuniculi do not provide immunity. ${ }^{6}$ Hyperimmune serum given to athymic mice failed to prevent lethal E. cuniculi infection. ${ }^{6}$ This supports that humoralmediated responses alone cannot confer protection against E. cuniculi in host cells. Experimental models show that humoral-mediated responses to E. cuniculi infection may be limited to augmenting opsonization-mediated destruction of infected cells. Antibody response variability has been demonstrated in human, primate, and rodent studies. ${ }^{6}$

E. cuniculi is an intracellular parasite, and T-cell mediated cytolytic processes that aim to eliminate infected cells from the host, appear to be most important in conferring resistance. ${ }^{6}$ Therefore, the humoral response of the production of antibodies (from B-cells) alone is not sufficient to prevent reinfection; it only indicates that the rabbit has a persistent $E$. cuniculi infection. Thus, a rabbit can be infected with E. cuniculi more than once in its lifetime. This point is very important to remember when trying to determine if an animal has been exposed to E. cuniculi when assessing a patient's serologic reactivity against $E$. cuniculi.

Most importantly, immunoglobulin G (IgG) antibody response variation has been demonstrated in experimentally infected rabbit models. In an experimental model of rabbits inoculated with E. cuniculi, three types of antibody responses were characterized as "short", "long", and "episodic" during a 68-day window of observation. ${ }^{28}$ These three different antibody responses revealed differing IgG titer patterns. Some rabbits had a plateau in IgG levels, others had a linear elevation in IgG levels, and one group had no detectable IgG levels at the end of 68 days. It is important to note that IgM, indicating acute infection, was the first antibody detected in all cases around 20-30 days post-exposure, and declined within 8-10 days. There was no consistent IgG pattern noted and therefore it was concluded that these differing responses may be influenced by E. cuniculi exposure load and individual variation in immune response.

In summary, the lifetime persistence of antibodies, lack of protective immunity from humoral-mediated responses, and variation in the antibody response of individual animals makes it nearly impossible to determine when an animal was exposed to E. cuniculi by solely measuring IgG serum antibodies.

\section{Clinical manifestation and histologic lesions: reconciling clinical signs with actual lesions}

Those veterinary practitioners who diagnose encephalitozoonosis in pet rabbits overwhelmingly report clinical neurologic disease as a hallmark of this disease. Neurologic presentations include vestibular disease, abrupt ataxia or hemiparesis, and/or mentation changes. One would presume that these clinical signs would naturally be associated with the degree of inflammation caused by the organism as it causes inflammation in neural tissue. Surprisingly, the severity of the inflammation seen histologically in affected rabbits does not mirror neurologic clinical signs.

\section{CNS lesions}

In E. cuniculi antibody-positive rabbits, reported clinical signs have been shown to have profound variability when correlated with histopathologic lesions. One comprehensive comparative study performed by Csokai et al in 2009 evaluated the histopathologic findings of E. cuniculi infection in correlation with clinical manifestations of the disease and highlighted this disparity. ${ }^{8}$ Severe inflammatory lesions found within the CNS tissue did not correlate with severe clinical signs of neurologic disease. The presence of significant cerebral inflammation and cerebral granuloma formation did not accompany clinical disease. These findings prohibited the conclusion that E. cuniculi infections were the sole cause of the neurologic symptoms and a definitive diagnosis could not be reached with antibody titers and clinical findings alone.

As central vestibular disease (brain stem and cerebellar localization) is typically more clinically apparent than cerebral disease, this may reflect why central vestibular disease is more commonly reported. Cerebral disease is more commonly diagnosed when the patient presents with seizures or cortical blindness. However, exclusive cerebral disease may also be limited to slight changes in mentation, which may be more difficult to identify with a neurologic examination. As abnormal spinal reflexes and central vestibular changes have clinically distinct presentations, veterinarians are more likely to report these signs as suggestive for E. cuniculi. Additionally, these clinical signs have been historically more commonly reported in 
the literature. E. cuniculi is not a differential diagnosis for peripheral vestibular disease.

\section{Non-CNS lesions}

In contrast with neurologic disease presentations, the presence of unilateral ocular disease is significantly correlated with E. cuniculi-induced phacoclastic uveitis. ${ }^{24-26}$ Because E. cuniculi and cell rupture induce inflammation in target organs (liver, lung, kidney, and heart, in addition to the CNS), one would expect to see histologic evidence of chronic inflammation on biopsy samples or at necropsy. Consequently, other diseases that affect these E. cuniculi-affected organs may cause more significant disease because $E$. cuniculi-associated inflammation has already compromised organ health. It is important to note that clinical signs may not be associated with organ disease severity. This disparity in clinical signs and histopathologic lesions is consistent with the findings of Csokai et al, ${ }^{8}$ reiterating the fact that antemortem diagnosis of E. cuniculi based on clinical signs remains challenging.

\section{Differential diagnoses}

Differential diagnoses for CNS clinical signs include infectious and noninfectious causes. Infectious causes of meningioencephalomyelitis include bacterial, viral, protozoal, and parasitic agents. Bacterial infections are more commonly reported, and include Pasteurella multocida, ${ }^{29}$ Staphylococcus aureus, Escherichia coli, Pseudomonas aeruginosa, and Listeria monocytogenes. ${ }^{29}$ Uncommon infectious diseases have been reported, and include Human Herpesvirus 1, ${ }^{30}$ Toxoplasma gondii, ${ }^{29}$ rabies, ${ }^{31}$ and Baylisascaris procyonis. ${ }^{29}$

Noninfectious entities include congenital, metabolic, neoplastic, inflammatory, toxic, traumatic causes, and vascular disease. Noninfectious differentials for CNS signs in pet rabbits include lymphosarcoma, lead toxicity, hydrocephalus, and cerebral infarcts. CNS clinical signs associated with the impairment of voluntary motor control of the limbs and lesions localized to the spine can be secondary to spinal infarcts, vertebral scoliosis, and vertebral fractures. Paresis, plegia, and ataxia can be due to focal spinal disease or result from disease anywhere along the cerebral-brainstem-spinal cord axis (see Table 3).

Clinical differential diagnoses (Table 3) for peripheral vestibular disease include bacterial otitis interna/externa, traumatic rupture to the tympanic bulla, aminoglycosidemediated ototoxicity, and idiopathic vestibular disease. Paroxysmal positional vertigo has been reported in humans and dogs; however, it has been postulated that this may account for the spontaneous onset of peripheral vestibular disease in some rabbits that have no evidence of an infectious cause for peripheral disease. ${ }^{32}$ Central vestibular disease may also be seen with bacterial, viral, protozoal, and verminous meningoencephalitis, lead toxicity, metastatic neoplasia, osteomyelitis of the petrous temporal bone, cerebral infarcts, hepatic encephalopathy, enterotoxemia, and sepsis.

E. cuniculi is rarely a cause of clinically appreciated primary renal dysfunction; however, chronic azotemia can be associated with weight loss and emaciation despite a normal dietary intake. The corresponding author has seen patients present with severe secondary clinical disease and with ultrasonographic evidence of acute onset in rabbits with chronic renal disease. Liver disease, cardiac disease, and respiratory disease are rarely reported as a cause of clinical signs associated with $E$. cuniculi infection, but studies have shown significant chronic inflammation and fibrosis reported as incidental findings in these organs on postmortem examination. ${ }^{8,11,16}$ Differential diagnoses for ocular disease include bacterial uveitis (unilateral disease is uncommon) and lensinduced uveitis secondary to geriatric cataract formation.

\section{Postmortem diagnosis}

Gross findings during necropsy examination are generally lacking in cases of encephalitozoonosis, with the exception of chronic nephritis (with fibrosis evidenced by subcapsular pitting and adherence of the capsule to the parenchyma). ${ }^{8}$ Histopathologic diagnosis of E. cuniculi begins with identifying inflammatory lesions suggestive of E. cuniculi on hematoxylin and eosin stain. This includes nonsuppurative (lymphoplasmacytic) to granulomatous encephalomyelitis, and lymphoplasmacytic to granulomatous infiltrates and accompanying fibrosis in target organs, such as the liver, lung, kidney, and heart. Occasionally spores within the parasitophorous vacuole can be identified, but their presence is best highlighted by a Gram's stain, generally revealing approximately $1.5 \times 2.5-5 \mu \mathrm{m}$ Gram-positive microsporidia. Figure 1 shows the presence of Gram-positive spores within the brainstem and Figure 2 within the spleen of a case seen at the Matthew J Ryan Veterinary Teaching Hospital at the University of Pennsylvania. Additional special stains can confirm the presence of mature E. cuniculi spores, including the Periodic Acid-Schiff stain, Ziehl Neelsen acid-fast stain, and modified trichrome stains. It has been shown that staining of inflammatory lesions with Ziehl Neelsen acid-fast stain provides increased sensitivity in detecting spores compared with hematoxylin and eosin stain alone ${ }^{8}$ however, there are no studies that compare Gram, Periodic Acid-Schiff, or other staining protocols. T. gondii, Sarcocystis spp, Pneumocystis 
Table 2 International overview of seroprevalence of $E$. cuniculi in rabbits

\begin{tabular}{|c|c|c|c|c|c|}
\hline Country & $\begin{array}{l}\text { Case } \\
\text { number }\end{array}$ & $\begin{array}{l}\text { Diagnostic } \\
\text { method }\end{array}$ & $\begin{array}{l}\text { Prevalence in } \\
\text { captive rabbits }\end{array}$ & $\begin{array}{l}\text { Prevalence in } \\
\text { wild rabbits }\end{array}$ & References \\
\hline \multirow[t]{3}{*}{ UK } & 97 & ELISA & $52 \%$ pets & & Keeble and Shaw $2006^{48}$ \\
\hline & 175 & IFAT & & $0 \%$ & Cox and Ross $1980^{49}$ \\
\hline & 180 & ELISA & $59.2 \%$ & & Harcount-Brown et al $2003^{50}$ \\
\hline \multirow[t]{2}{*}{ Italy } & 1,600 & CIA, ELISA & $31.6 \%$ farmed & & Santaniello et al $2009^{51}$ \\
\hline & 125 & ELISA, CIA & $67.2 \%$ pets & & Dipineto $2008^{52}$ \\
\hline \multirow[t]{2}{*}{ Switzerland } & 72 & IFAT, ELISA & $84.7 \%$ pets & & Muller $1998^{53}$ \\
\hline & 292 & & $7.5 \%$ farmed & & \\
\hline France & 204 & IFAT & & $3.9 \%$ & Chalupsky et al $1990^{54}$ \\
\hline Austria & 71 & IFAT & $50 \%-69.7 \%$ & & Csokai et al $2009^{55}$ \\
\hline Germany & 277 & $\mathrm{CIA}$ & $41.7 \%$ pets & & Ewringmann and Gobel $1999^{56}$ \\
\hline Slovakia & 571 & IFAT & $41.7 \%$ & & Halanova et al $2003^{57}$ \\
\hline Norway & 66 & $\mathrm{CIA}$ & $73 \%$ breeders & & Lyngset $1980^{58}$ \\
\hline \multirow[t]{2}{*}{ Japan } & 337 & ELISA & $63.5 \% \operatorname{lgG}, 28.5 \% \lg M$ & & Igarashi et al $2008^{59}$ \\
\hline & & $\lg G, \lg M$ & & & \\
\hline Taiwan & 171 & CIA, ELISA & $63.2 \%$ CIA $67.8 \%$ ELISA & & Tee et al $2011^{60}$ \\
\hline Turkey & 150 & $\mathrm{CIA}$ & $65.3 \% \mathrm{lab}$ & & Eroksuz 199961 \\
\hline Nigeria & 237 & IFAT & $16.7 \%$ & & Okewole $2008^{62}$ \\
\hline Egypt & 240 & ELISA & $15 \%$ & & Ashmawy et al $2011^{63}$ \\
\hline Australia & 823 & IFAT & & $0 \%$ & Cox et al $1980^{64}$ \\
\hline \multirow[t]{2}{*}{ US } & 203 & Prospective & $62 \%$ (47\% localized & & Cray $2009^{65}$ \\
\hline & & ELISA & from one shelter) & & \\
\hline
\end{tabular}

Abbreviations: CIA, carbon immunoassay; ELISA, enzyme-linked immunosorbent assay; IFAT, indirect fluorescent antibody technique; IgG, immunoglobulin G; IgM, immunoglobulin $M$.

spp, Cryptosporidium cuniculi, and Neospora caninum may have a similar histologic appearance, but do not take up Gram's stain. Differentiation from Gram-positive bacteria is generally based on morphology as well as the type of inflammation, and other histochemical stains (Periodic Acid-Schiff, acid-fast) can be used when results are equivocal.

Additional techniques can be used for a more definitive diagnosis, including immunohistochemistry as well as nested polymerase chain reaction (PCR). There are occasions when

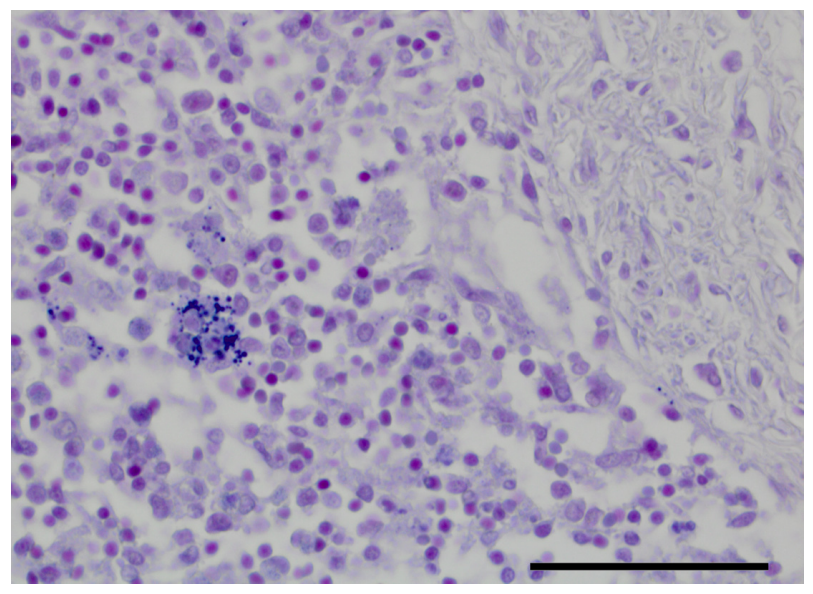

Figure 2 Spleen: a macrophage within the splenic parenchyma contains phagocytosed spores, which may be obscured in a highly cellular background (hematoxylin and eosin stain, 400x, bar $50 \mu \mathrm{m}$ ). These spores are highlighted by Gram's stain. $(600 \times$ magnification, bar $33 \mu \mathrm{m})$.
E. cuniculi spores are not identified in the tissue examined, and the pathologist is left to make a diagnosis based on evidence of characteristic inflammatory lesions consistent with encephalitozoonosis. Although more definitive evidence of infection may be achieved with nested PCR, with improved sensitivity and specificity of organism detection compared with examination of tissue stained with hematoxylin and eosin, ${ }^{8}$ it may be underutilized due to limited commercial availability or the financial limitations of institutions and pet owners.

Merogeny, sporogeny, and spore dissemination with rupture of the host cells is accompanied by moderate to marked chronic lymphoplasmatic to granulomatous inflammation. ${ }^{11}$ In the CNS of rabbits, common histologic findings include focal or multifocal random nonsuppurative to granulomatous meningoencephalomyelitis with gliosis and astrocytosis. In the kidney, characteristic chronic inflammatory lesions include focal to segmental lymphoplasmacytic tubulointerstitial nephritis. In the liver, lymphoplasmacytic hepatitis, cholangiohepatitis, and portal hepatitis are commonly diagnosed. Pulmonary lesions are often characterized as chronic lymphocytic interstitial pneumonia.

\section{Antemortem diagnosis}

As evidenced by the histologic distribution of E. cuniculi lesions, variance in presentation of clinical signs, and the 
unique host immune response, the diagnosis of E. cuniculi can be admittedly challenging in the clinical patient. The importance of appropriately ruling out differential causes of disease in rabbits cannot be overstated. The clinician's current repertoire of diagnostic options has a very limited ability to link serologic titers to disease severity clinically, detect urinary excretion of spores, and/or utilize sentinel diagnostics for confirmation of neurologic inflammation definitive for E. cuniculi. The sensitivity and specificity of PCR for detecting E. cuniculi in the lens capsules of animals presenting with phacoclastic uveitis, is arguably, the most definitive diagnostic tool available for antemortem diagnosis of clinical E. cuniculi disease in pet rabbits.

\section{Serology}

Serology is one of the antemortem diagnostics employed to confirm exposure to the E. cuniculi organism. Serologic titers for E. cuniculi are usually reported using enzyme-linked immunosorbent assay (ELISA), indirect fluorescent antibody technique, and carbon immunoassay methods. Fluorescent antibody technique and ELISA results have been shown to be comparable. ${ }^{33}$ The interpretation of serum antibody titers can be difficult in clinical cases, and at best documents exposure to the organism. A single seropositive test result can be seen in animals that are exposed, exposed and have recovered from infection, or are infected with or without signs of clinical disease. Several studies ${ }^{3,434,35}$ have subsequently evaluated the usefulness of ELISA titers (IgG, IgM) and protein electrophoresis as diagnostic aids for E. cuniculi infection in rabbits. All of these studies recommend that more than one titer be obtained to ascertain exposure and acute infection status, although IgM is the only antibody that truly indicates acute infection.

In a study that evaluated the usefulness of ELISA titers, PCR, and special stains as diagnostic aids for E. cuniculi, Csokai et $\mathrm{al}^{4}$ found that there was no difference in the IgG seropositive status of animals presenting with E. cuniculi clinical signs and asymptomatic animals. Cray et $\mathrm{al}^{3}$ present data suggesting that there is evidence of increased IgG ELISA titers in E. cuniculi suspect animals experiencing neurologic clinical signs and that gamma globulin elevations on protein electrophoresis may also aid in the antemortem diagnosis of clinical E. cuniculi infections. In a seroepidemiologic study of 500 rabbits, Jeklova et $\mathrm{al}^{34}$ found that there was a difference in the IgM serostatus of animals presenting with clinical signs $(32.4 \%)$ that were likely suffering from acute exposure or reinfection and clinical disease, as compared with the $\operatorname{IgM}$ serostatus of healthy animals $(24.2 \%)$. IgG titers were seen in $68 \%$ of all samples. The authors recommend screening for IgM titers, in addition to IgG titers, to help differentiate between acute infections and chronic/latent infections.

In an experimental oral and ocular infection model, ${ }^{35}$ IgG titers and IgM titers corresponded to dose-dependent administration of $E$. cuniculi spores. Those orally dosed with $1 \times 10^{7}$ spores had IgM elevations spike within the first week and IgG titers spike by the third week. Both IgG and IgM remained significantly elevated until week 18 post-exposure. Those rabbits that received a high ocular dose $\left(1 \times 10^{7}\right.$ spores $)$ displayed the same $\operatorname{IgG}$ and $\operatorname{IgM}$ elevations and patterns as noted for orally infected rabbits. ${ }^{35}$

Based on these findings, we can conclude the following. A single negative IgG titer result in a healthy animal may mean that the animal has not been exposed or that the animal may have been recently exposed and will not show titers for another 2 weeks. A second negative titer in the same healthy animal, 3 weeks later, confirms nonexposure. This does not hold true for immunocompromised animals. In immunocompetent animals with neurologic signs that have two negative IgG titers 3 weeks apart, E. cuniculi can be ruled out as a cause of clinical signs. In healthy animals with a single positive IgG titer, this could indicate early infection (with 3 weeks post-exposure), chronic infection, and/or previous infection and recovery from $E$. cuniculi. In animals with an acute $E$. cuniculi exposure, IgM titers will be elevated from day 0 to 35 post-exposure and can persist for up to 18 weeks in rabbits. Therefore, if there is a positive IgM titer, the animal may need to be isolated from others as it may shed spores in the urine for up to 18 weeks. After 5-18 weeks, IgM titers will likely wane and no longer be helpful in determining if the animal is suffering from an acute infection.

\section{Seroprevalence}

There are several studies that have evaluated the seroprevalence of E. cuniculi in pet and wild rabbit populations. ${ }^{11}$ One study sought to evaluate estimates of E. cuniculi seroprevalence in pet rabbits in the US. ${ }^{3}$ Extensive review of the literature reveals that the prevalence of E. cuniculi is indeed a global concern not only for pet rabbits but also for humans. Table 2 provides a summary of international prevalence studies.

\section{Polymerase chain reaction}

PCR detection of spore DNA has been attempted in ocular material recovered from phacoclastic uveitis, target organ tissue, urine, and cerebrospinal fluid to aid in E. cuniculi detection on postmortem histologic tissue examination. Of 
Table 3 Differential diagnoses for Encephalitozoon cuniculi in pet rabbits

\begin{tabular}{|c|c|c|}
\hline $\begin{array}{l}\text { Clinical } \\
\text { presentation }\end{array}$ & $\begin{array}{l}\text { Infectious } \\
\text { differentials }\end{array}$ & $\begin{array}{l}\text { Noninfectious } \\
\text { differentials }\end{array}$ \\
\hline $\begin{array}{l}\text { CNS } \\
\text { impairment }\end{array}$ & $\begin{array}{l}\text { Pasteurella multocida, } \\
\text { Staphylococcus aureus, } \\
\text { Escherichia coli, } \\
\text { Pseudomonas aeruginosa, } \\
\text { and Listeria moncytogenes } \\
\text { Uncommon: Human } \\
\text { Herpesvirus-I, } \\
\text { Toxoplasma gondii, rabies, } \\
\text { and Baylisascaris procyonis }\end{array}$ & $\begin{array}{l}\text { Lymphosarcoma, lead } \\
\text { toxicity, hydrocephalus, } \\
\text { cerebral infarcts, spinal } \\
\text { infarcts, vertebral } \\
\text { scoliosis, and vertebral } \\
\text { fractures }\end{array}$ \\
\hline $\begin{array}{l}\text { Central } \\
\text { vestibular } \\
\text { disease }\end{array}$ & $\begin{array}{l}\text { Bacterial, viral, } \\
\text { protozoal, } \\
\text { and verminous } \\
\text { meningioencephalitis, } \\
\text { Enterotoxemia, sepsis }\end{array}$ & $\begin{array}{l}\text { Lead toxicity, } \\
\text { metastatic neoplasia, } \\
\text { osteomyelitis of the } \\
\text { petrous temporal bone, } \\
\text { cerebral infarcts, and } \\
\text { hepatic encephalopathy }\end{array}$ \\
\hline $\begin{array}{l}\text { Ocular } \\
\text { disease }\end{array}$ & $\begin{array}{l}\text { Bacterial uveitis } \\
\text { (unilateral disease } \\
\text { is uncommon) }\end{array}$ & $\begin{array}{l}\text { Lens-induced uveitis } \\
\text { caused by geriatric } \\
\text { cataract formation }\end{array}$ \\
\hline
\end{tabular}

Note: Peripheral vestibular disease is not a differential for Encephalitozoon cuniculi. Abbreviation: CNS, central nervous system.

all tests, PCR appears to be highly specific and sensitive for the detection of E. cuniculi in ocular contents of rabbits suffering from phacoclastic uveitis. ${ }^{7,824}$ This is thought to be because the increased number of spores in the lens improves DNA recovery for PCR.

PCR spore detection in cerebrospinal fluid samples has demonstrated variable sensitivity. Jass et al ${ }^{36}$ evaluated the usefulness of cerebrospinal fluid analysis to aid in E. cuniculi detection. In 21 E. cuniculi suspect rabbits (clinical vestibular disease and/or paresis), E. cuniculi rabbits demonstrated lymphomonocytic pleocytosis and increased protein levels. Because this may be seen with other infections, these findings cannot be used as a sole diagnostic for E. cuniculi. In the same study, PCR detected E. cuniculi spore DNA in $39.5 \%$ of cerebrospinal fluid samples. In another study that evaluated the clinical symptoms and diagnosis of $E$. cuniculi infection in rabbits, Kunzel et al ${ }^{7}$ reported that urine and cerebrospinal fluid samples were negative for all samples in seropositive animals. Csokai et $\mathrm{al}^{4}$ reported that nested PCR detected E. cuniculi in $0 \%$ of cerebrospinal fluid samples and in $29.7 \%$ of urine samples. PCR spore detection was positive in $48.7 \%$ of urine samples from 18 rabbits in a study evaluating short-term and long-term survival outcomes in infected rabbits performed by Sieg et al. ${ }^{12}$ Evaluation of nested PCR of tissue has been shown to be less sensitive than histologic tissue evaluation.

Finally, Jeklova et $\mathrm{al}^{35}$ demonstrated PCR spore recovery in experimentally infected rabbits via ocular and oral transmission to evaluate urine excretion of spores in infected rabbits. In those infected with $1 \times 10^{3}$ spores (low dose) either ocularly or orally, no spores were detected in the urine. For those dosed at $1 \times 10^{7}$ spores, spores were found in the urine at 7 days in the orally infected group and at 14 days in the ocularly infected group. Shedding persisted and declined at 12 weeks after infection, becoming sporadic within 13-18 weeks. Cerebrospinal fluid spores were not detected in any of the groups in this study.

In summary, at this time, it appears that PCR is an unreliable diagnostic test for in vivo detection of E. cuniculi in body fluids and tissues, other than in the ocular contents of rabbits with phacoclastic uveitis., ${ }^{4,11}$ When interpreting PCR results, it is important to note that PCR spore detection will rely heavily on stage of infection (acute, latent, or reinfection) and by dose-dependent spore burden within the patient. Cox et al have demonstrated that urine spore excretion declines and ceases in acutely infected rabbits at 98 days post-infection. ${ }^{14}$ Urine excretion and elimination rates will need to be studied in chronically infected rabbits to ascertain the true value of PCR urine spore detection. As revealed by Kunzel et $\mathrm{al},{ }^{7}$ PCR spore detection in cerebrospinal fluid or urine samples in seropositive animals can result in false negative results.

\section{Urine staining}

Jass et $\mathrm{al}^{36}$ reported positive trichrome staining of urinary spores in $24 \%$ of animals in the aforementioned study evaluating cerebrospinal fluid. Fluorescent staining has also been recommended for spore detection in the urine, as performed in human cases of encephalitozoonosis. Because spore excretion can occur sporadically after acute infection, there is a decreased sensitivity associated with E. cuniculi detection in chronically infected rabbits.

\section{Ancillary diagnostics}

Biochemistry screening, complete blood count evaluation, and routine urinalysis will diagnostically aid the management of concurrent disease states that may be exacerbated by the chronic effects of E. cuniculi infection. Advanced imaging should be performed to rule out differential diagnoses for neurologic rabbits, including radiographs, computed topography, and magnetic resonance imaging.

\section{Treatment and control}

\section{Treatment}

Clinical signs associated with E. cuniculi infection may or may not be associated with the presence of intracellular spores, but it is definitively associated with the inflammation accompanying ruptured host cells. Therefore, treatment goals 
should include reduction of spore proliferation and migration, reduction of spore-mediated inflammation, management of concurrent disease, and management of severe neurologic clinical signs.

To date, there are only three controlled studies that have evaluated the efficacy of treatment in E. cuniculi-infected rabbits. ${ }^{7,10,12,37}$ As E. cuniculi is classified as a microsporidian (with both fungal and protozoal characteristics), in vitro studies demonstrate spore susceptibility to a number of antifungal and benzimidazole medications. ${ }^{38}$

\section{Ocular disease}

Erwingmann et $\mathrm{al}^{37}$ demonstrated successful conservative treatment of a reactive uveitis secondary to lens rupture due to lenticular E. cuniculi infection in pet rabbits utilizing systemically administered dexamethasone and oxytetracycline in conjunction with topical ophthalmic dexamethasone and tetracycline. The uveitis resolved, but the focal granuloma and cataracts persisted. Surgical removal of the lens by phacoemulsification and medical treatment is considered the treatment of choice for affected rabbits. ${ }^{25,26}$ It is known that systemic administration of dexamethasone in rodent models can cause profound immunosuppression and may exacerbate systemic disease caused by E. cuniculi. ${ }^{39}$ Because ocular administration of dexamethasone phosphate disodium has been shown to result in systemic absorption in rabbits, extreme caution should be taken before ocular administration. ${ }^{40}$ A topical nonsteroidal anti-inflammatory drug may be a safer choice if renal values are within normal limits.

\section{Systemic disease}

In humans, albendazole is used to decrease spore counts during microsporidial infection, however there are some cases that report relapse of urinary shedding after treatment. ${ }^{41}$ Pharmacokinetics of orally and intraperitoneally administered albendazole has been evaluated in New Zealand White rabbits. ${ }^{40}$ A pharmacodynamic study has not evaluated the efficacy of orally administered albendazole in the treatment of E. cuniculi, and albendazole has been shown to be embryotoxic and teratogenic in rabbits and can cause liver disease with prolonged use in several animal species. ${ }^{42}$ Although the pharmacokinetics of fenbendazole has just recently been characterized in rabbits, ${ }^{43}$ fenbendazole has been evaluated in the treatment and elimination of E. cuniculi in rabbits in two controlled studies. ${ }^{10,12}$

Suter et $\mathrm{al}^{10}$ demonstrated the prevention of E. cuniculi infection with prophylactic administration of fenbendazole prior to experimental infection. Rabbits remained seronegative after 21 days and spores were not recovered in brain tissue on postmortem tissue analysis. Information regarding spore recovery from the kidney and histologic analysis for any tissue was not provided. In the therapeutic trial of fenbendazole orally dosed at $20 \mathrm{mg} / \mathrm{kg}$ body weight daily for 4 weeks, there were no spores noted in the brain based on histologic evaluation. Based on these findings, current treatment practices advocate the off-label use of fenbendazole for E. cuniculi prevention. Some advocate the use of fenbendazole for the treatment of chronic E. cuniculi infections in rabbits, but no controlled study has truly confirmed the clinical efficacy of this medication in chronic cases that already have advanced CNS inflammation.

In addition to benzimidazole therapy aimed at spore reduction, recommendations for reducing the severe inflammation associated with host cell rupture have been anecdotally reported. The use of systemic steroid therapy, although controversial, has been advocated to reduce severe CNS inflammation. The immunosuppressive effects of steroid administration in rabbits have been well documented in the literature. ${ }^{44}$ According to an immunosuppression model in rabbits performed by Jeklova et al, ${ }^{44}$ dexamethasone administered at $2 \mathrm{mg} / \mathrm{kg}$ intramuscularly for three doses every 6 hours causes a significant decrease in circulating lymphocyte counts and reduces the reactive oxygen activity of heterophils for 72 hours. In a second study, Jeklova et $\mathrm{al}^{35}$ demonstrated that acute immunosuppression can be induced with this same dexamethasone regimen and exacerbate and/or cause clinical signs in E. cuniculi-infected rabbits. Few controlled studies have evaluated the dose-response and immunosuppressive effects of dexamethasone in pet rabbits administered doses lower than $2 \mathrm{mg} / \mathrm{kg}$. We discourage the use of dexamethasone to treat E. cuniculi-mediated inflammation and in the treatment of head trauma secondary to axial or longitudinal rolling for three major reasons. First, its use in the management of cerebral trauma is no longer recommended for use in humans. ${ }^{45}$ Second, dexamethasone has been shown to reduce the efficacy of albendazole in reducing spore migration and host cell rupture, and to potentiate disease severity in experimental rodent models of E. cuniculi infection. ${ }^{39}$ Lastly, it has not been shown to have a therapeutic effect in chronically infected companion rabbits. ${ }^{12}$

Kunzel et $\mathrm{al}^{7}$ evaluated the therapeutic efficacy of combined treatment of fenbendazole, oxytetracycline, enrofloxacin, and dexamethasone or prednisone, and reported a $54.2 \%$ clinical recovery rate. A recent study, conducted by Sieg et al, has evaluated the clinical efficacy of fenbendazole, oxytetracycline, and steroid therapy. ${ }^{12}$ There was no significant difference in the long-term or short-term 
survival or in neurologic sign reduction in rabbits receiving the following treatment combinations: oxytetracycline + dexamethasone, fenbendazole + dexamethasone, fenbendazole + oxytetracycline + dexamethasone, and oxytetracycline alone. Dexamethasone did not appear to have a therapeutic effect. Survival analysis performed for those rabbits that received fenbendazole demonstrated that they were 1.6 times more likely to survive until day 10 compared with rabbits that did not receive fenbendazole in their treatment protocol. After day 10 , there was no consistency in the efficacy of fenbendazole. This demonstrates the need for more controlled studies that histologically demonstrate spore reduction based on the treatment protocol.

Because the risk of steroid-induced immunosuppression is significant in E. cuniculi-infected animals, ${ }^{35,39}$ we suggest the use of systemic nonsteroidal anti-inflammatory drugs instead of steroids to manage inflammation. Nonsteroidal anti-inflammatory drug therapy should also be used cautiously in animals that have concurrent renal disease because the kidney is a target organ for E. cuniculi-associated inflammation. The use of midazolam or diazepam is commonly employed to control seizure activity and to act as a mild sedative in animals with severe vestibular disease that is causing flailing/rolling. Environmental modifications should be made to provide severely centrally vestibular animals with protection. Soft padding and nonmetal cage barriers should be employed with these animals to prevent accidental ocular and limb trauma.

\section{Control}

Control will be essential in reducing the spread of this opportunistic pathogen, not only to other rabbits, but also reducing E. cuniculi contact in immunocompromised humans. Assessment of titer status, in the face of elevated IgM titers, may help delineate the shedding timeline of rabbits undergoing an active infection. Preventative antimicrosporidial medications have also been advised based on studies that reduced brain spore isolation in experimentally infected rabbits. ${ }^{10}$ In addition to monitoring the potential window for excretion and disease contraction in pet rabbits, environmental disinfection becomes essential for disease control.

E. cuniculi is environmentally resistant, but spores can be killed effectively using a number of disinfection protocols. ${ }^{46}$ Spores are susceptible to $0.1 \%$ bleach at a contact time of 10 minutes, and ethanol (70\%) effectively kills spores with a contact time of 30 seconds. ${ }^{47}$ Sodium hydroxide (1\%), formaldehyde $(0.3 \%)$, and hydrogen peroxide ( $1 \%$ ) effectively kill spores with a contact time of 30 minutes. $^{47}$

\section{Summary}

E. cuniculi is a significant microsporidial disease in pet rabbits and has been shown to be an opportunistic pathogen in immunocompromised humans. Current seroprevalence studies demonstrate that E. cuniculi significantly affects the global population of captive rabbits. Seroprevalence and histologic data confirming the prevalence of E. cuniculi in the US are lacking. The pathogen's ability to evade the humoral-mediated immune response affords it the luxury of causing chronic neurologic and renal disease in pet rabbits and makes serologic titer interpretation difficult, because serologic titers do not correlate with disease severity. Serologic IgM titers and IgG titers may aid in the determination of disease stage in infected patients. Controlled studies evaluating the efficacy of current treatment goals aimed at spore reduction are limited, and current practice standards suggest the use of fenbendazole. Steroid therapy is contraindicated due to its significant immunosuppressive effects and its limited efficacy in improving the survival outcome of patients or in reducing neurologic clinical signs. Environmental control can be achieved using a number of widely available disinfection protocols.

\section{Acknowledgment}

The authors would like to thank Drury Reavill at the Zoo/ Exotic Pathology Service, West Sacramento, CA, for her postmortem data, mentorship, and support with this publication.

\section{Disclosure}

The authors report no conflicts of interest in this work.

\section{References}

1. Deplazes P, Mathis A, Baumgartner R, Tanner I, Weber R. Immunologic and molecular characteristics of encephalitozoon-like microsporidia isolated from humans and rabbits indicate that Encephalitozoon cuniculi is a zoonotic parasite. Clin Infect Dis. 1996;22(3):557-559.

2. Mathis A, Weber R, Deplazes P. Zoonotic potential of the microsporidia. Clin Microbiol Rev. 2005;18(3):423-445.

3. Cray C, Arcia G, Schneider R, Kelleher SA, Arheart KL. Evaluation of the usefulness of an ELISA and protein electrophoresis in the diagnosis of Encephalitozoon cuniculi infection in rabbits. Am J Vet Res. 2009;70(4):478-482.

4. Csokai J, Joachim A, Gruber A, Tichy A, Pakozdy A, Kunzel F. Diagnostic markers for encephalitozoonosis in pet rabbits. Vet Parasitol. 2009;163(1-2):18-26.

5. Bywater JE, Kellett BS. Humoral immune response to natural infection with Encephalitozoon cuniculi in rabbits. Lab Anim. 1979;13(4): 293-297.

6. Valencakova A, Halanova M. Immune response to encephalitozoon infection review. Comp Immunol Microbiol Infect Dis. 2012;35(1):1-7.

7. Kunzel F, Gruber A, Tichy A, et al. Clinical symptoms and diagnosis of encephalitozoonosis in pet rabbits. Vet Parasitol. 2008;151(2-4): $115-124$

8. Csokai J, Gruber A, Kunzel F, Tichy A, Joachim A. Encephalitozoonosis in pet rabbits (Oryctolagus cuniculus): pathohistological findings in animals with latent infection versus clinical manifestation. Parasitol Res. 2009;104(3):629-635. 
9. Gruber A, Pakozdy A, Weissenbock H, Csokai J, Kunzel F. A retrospective study of neurological disease in 118 rabbits. $J$ Comp Pathol. 2009;140(1):31-37.

10. Suter C, Muller-Doblies UU, Hatt JM, Deplazes P. Prevention and treatment of Encephalitozoon cuniculi infection in rabbits with fenbendazole. Vet Rec. 2001;148(15):478-480.

11. Kunzel F, Joachim A. Encephalitozoonosis in rabbits. Parasitol Res. 2010;106(2):299-309.

12. Sieg J, Hein J, Jass A, Sauter-Louis C, Hartmann K, Fischer A. Clinical evaluation of therapeutic success in rabbits with suspected encephalitozoonosis. Vet Parasitol. 2012;187(1-2):328-332.

13. Wright JH, Craighead EM. Infectious motor paralysis in young rabbits. J Exp Med. 1922;36(1):135-140.

14. Cox JC, Hamilton RC, Attwood HD. An investigation of the route and progression of Encephalitozoon cuniculi infection in adult rabbits. J Protozool. 1979;26(2):260-265.

15. Bohne W, Bottcher K, Gross U. The parasitophorous vacuole of Encephalitozoon cuniculi: biogenesis and characteristics of the host cell-pathogen interface. Int J Med Microbiol. 2011;301(5):395-399.

16. Wasson K, Peper RL. Mammalian microsporidiosis. Vet Pathol. 2000;37(2):113-128.

17. Orlik J, Böttcher K, Groß U, Bohne W. Germination of phagocytosed E. cuniculi spores does not significantly contribute to parasitophorous vacuole formation in J774 cells. Parasitol Res. 2010;106(3):753-755.

18. Didier ES, Didier PJ, Snowden KF, Shadduck JA. Microsporidiosis in mammals. Microbes Infect. 2000;2(6):709-720.

19. Owen DG, Gannon J. Investigation into the transplacental transmission of Encephalitozoon cuniculi in rabbits. Lab Anim. 1980;14(1):35-38.

20. Cox JC, Gallichio HA. Serological and histological studies on adult rabbits with recent, naturally acquired encephalitozoonosis. Res Vet Sci. 1978;24(2):260-261.

21. Khan IA, Schwartzman JD, Kasper LH, Moretto M. CD8+ CTLs are essential for protective immunity against Encephalitozoon cuniculi infection. J Immunol. 1999;62(10):6086-6091.

22. Couzinet S, Cejas E, Schittny J, Deplazes P, Weber R, Zimmerli S. Phagocytic uptake of Encephalitozoon cuniculi by nonprofessional phagocytes. Infect Immun. 2000;68(12):6939-6945.

23. Franzen C, Müller A, Hartmann P, Salzberger B. Cell invasion and intracellular fate of Encephalitozoon cuniculi (Microsporidia). Parasitology. 2005;130(3):285-292.

24. Wolfe J. Phacoclastic uveitis in the rabbit. Prog Vet Comp Ophthalmol. 1993;3:92.

25. Stiles J, Didier E, Ritchie B. Encephalitozoon cuniculi in the lens of a rabbit with phacoclastic uveitis: confirmation and treatment. Veterinary and Comparative Ophthalmology. 1997;7:233-238.

26. Felchle LM, Sigler RL. Phacoemulsification for the management of Encephalitozoon cuniculi-induced phacoclastic uveitis in a rabbit. Vet Ophthalmol. 2002;5(3):211-215.

27. Giordano C, Weigt A, Vercelli A, Rondena M, Grilli G, Giudice C. Immunohistochemical identification of Encephalitozoon cuniculi in phacoclastic uveitis in four rabbits. Vet Ophthalmol. 2005;8(4): 271-275.

28. Kunstyr I, Lev L, Naumann S. Humoral antibody response of rabbits to experimental infection with Encephalitozoon cuniculi. Vet Parasitol. 1986;21(4):223-232.

29. Percy DH, Barthold SW. Rabbit. In: Pathology of Laboratory Rodents and Rabbits. Volume 253. 3rd ed. Ames, IA: Blackwell Publishing; 2007.

30. Muller K, Fuchs W, Heblinski N, et al. Encephalitis in a rabbit caused by human herpesvirus-1. J Am Vet Med Assoc. 2009;235(1):66-69.

31. Eidson M, Matthews SD, Willsey AL, Cherry B, Rudd RJ, Trimarchi CV. Rabies virus infection in a pet guinea pig and seven pet rabbits. $J \mathrm{Am}$ Vet Med Assoc. 2005;227(6):932-935.

32. Rhody J. Which way is up, doc? In: 84th Annual Western Veterinary Conference. 2012 WVC Scientific Program.

33. Boot R, Hansen AK, Hansen CK, Nozari N, Thuis HC. Comparison of assays for antibodies to Encephalitozoon cuniculi in rabbits. Lab Anim. 2000;34(3):281-289.
34. Jeklova E, Jekl V, Kovarcik K, et al. Usefulness of detection of specific $\mathrm{IgM}$ and $\mathrm{IgG}$ antibodies for diagnosis of clinical encephalitozoonosis in pet rabbits. Vet Parasitol. 2010;170(1-2):143-148.

35. Jeklova E, Leva L, Kovarcik K, et al. Experimental oral and ocular Encephalitozoon cuniculi infection in rabbits. Parasitology. 2010;137(12):1749-1757.

36. Jass A, Matiasek K, Henke J, Kuchenhoff H, Hartmann K, Fischer A. Analysis of cerebrospinal fluid in healthy rabbits and rabbits with clinically suspected encephalitozoonosis. Vet Rec. 2008;162(19):618-622.

37. Erwingmann A, Göbel T. Untersuchugen zur Klinik und Therapie der Encephalitozoonose beim Heimtierkaninchen. [Examinations on clinics and therapy of encephalitozoonosis in pet rabbits.] Kleintierpraxis. 1999;44:357-372. German.

38. Franssen FF, Lumeij JT, van Knapen F. Susceptibility of Encephalitozoon cuniculi to several drugs in vitro. Antimicrob Agents Chemother. 1995;39(6):1265-1268.

39. Lallo MA, dos Santos MJ, Bondan EF. Infecção experimental pelo Encephalitozoon cuniculi em camundongos imunossuprimidos com dexametasona. [Experimental Encephalitozoon cuniculi infection in dexamethasone-immunosuppressed mice.] Rev Saude Publica. 2006;36(5):621-626. Portuguese.

40. Rosenblum C, Dengler RE Jr, Geoffroy RF. Ocular absorption of dexamethasone phosphate disodium by the rabbit. Arch Ophthalmol. 1967;77(2):234-237.

41. Talabani H, Sarfati C, Pillebout E, van Gool T, Derouin F, Menotti J. Disseminated infection with a new genovar of Encephalitozoon cuniculi in a renal transplant recipient. J Clin Microbiol. 2010;48(7):2651-2653.

42. Kotler DP, Orenstein JM. Clinical syndromes associated with microsporidiosis. Adv Parasitol. 1998;40:321-349.

43. Zhu X, Wang S, Liu Q, et al. Simultaneous determination of benzimidazoles and their metabolites in plasma using high-performance liquid chromatography/tandem mass spectrometry: application to pharmacokinetic studies in rabbits. $J A O A C$ Int. 2011;94(3):839-846.

44. Jeklova E, Leva L, Jaglic Z, Faldyna M. Dexamethasone-induced immunosuppression: a rabbit model. Vet Immunol Immunopathol. 2008;122(3-4):231-240.

45. Edwards P, Arango M, Balica L, et al. Final results of MRC CRASH, a randomised placebo-controlled trial of intravenous corticosteroid in adults with head injury-outcomes at 6 months. Lancet. 2005;365(9475): 1957-1959.

46. Waller T, Lyngset A, Morein B. Diagnosis of encephalitozoonosis: a simple method for collection of rabbit blood. Lab Anim. 1979;13(3): 207-208.

47. Jordan CN, Dicristina JA, Lindsay DS. Activity of bleach, ethanol and two commercial disinfectants against spores of Encephalitozoon cuniculi. Vet Parasitol. 2006;136(3-4):343-346.

48. Keeble EJ, Shaw DJ. Seroprevalence of antibodies to Encephalitozoon cuniculi in domestic rabbits in the United Kingdom. Vet Rec. 2006;158(16):539-544.

49. Cox JC, Ross J. A serological survey of Encephalitozoon cuniculi infection in the wild rabbit in England and Scotland. Res Vet Sci. 1980;28(3);396.

50. Harcourt-Brown FM, Holloway HKR. Encephalitozoon cuniculi in pet rabbits. Vet Rec. 2003;152(14):427-431.

51. Santaniello A, Dipineto L, Rinaldi L, Menna LF, Cringoli G, Fioretti A. Serological survey of Encephalitozoon cuniculi in farm rabbits in Italy. Res Vet Sci. 2009;87(1):67-69.

52. Dipineto L, Rinaldi L, Santaniello A, et al. Serological survey for antibodies to Encephalitozoon cuniculi in pet rabbits in Italy. Zoonoses and Public Health. 2008;55(3):173-175.

53. Muller C (1998). Untersuchungen zur Diagnostik, Biologie und Verbreitung von Microsporidien bei Kaninchen und anderen Tierarten. [Studies on diagnosis, biology and distribution of microsporidia in rabbits and other species]. Dissertation, University of Zürich. German.

54. Chalupský J, Vávra J, Gaudin JC, et al. Mise en évidence sérologique de la présence d'encéphalitozoonose et de toxoplasmose chez le lapin de Garenne (Oryctolagus cuniculus) en France. [Serological evidence of the occurrence of encephalitozoonosis and toxoplasmosis in the European wild rabbit (Oryctolagus cuniculus) in France.] Bulletin de la Société Française de Parasitologie. 1990;8(1):91-95. French. 
55. Csokai J, Gruber A, Künzel F, Tichy A, Joachim A. Encephalitozoonosis in pet rabbits (Oryctolagus cuniculus): pathohistological findings in animals with latent infection versus clinical manifestation. Parasitol Res. 2009;104(3):629-635.

56. Ewringmann A, Gobel T. Examinations on clinics and therapy of encephalitozoonosis in pet rabbits. Kleintierpraxis. 1999;44(5):357.

57. Halánová M, Cisláková L, Valencákova A, Bálent P, Adam J, Trávnicek M. Serological screening of occurrence of antibodies to Encephalitozoon cuniculi in humans and animals in Eastern Slovakia. Ann Agric Environ Med. 2003;10(1):117.

58. Lyngset A. A survey of serum antibodies to Encephalitozoon cuniculi in breeding rabbits and their young. Lab Anim Sci. 1980; 30(3):558-561.

59. Igarashi M, Oohashi E, Dautu G, Ueno A, Kariya T, Furuya K. High seroprevalence of Encephalitozoon cuniculi in pet rabbits in Japan. J Vet Med Sci. 2008;70(12):1301-1304.

60. Tee KY, Kao JP, Chiu HY, et al. Serological survey for antibodies to Encephalitozoon cuniculi in rabbits in Taiwan. Vet Parasitol. 2011;183(1):68-71.
61. Eroksuz Y, Eroksuz H, Ozer H, Cevik A, Unver O. A Survey of Encephalitozoon Cumculi Infechon in Rabbit Colonies in Elazig, Turkey: Pathomorphologic and Serologic (Carbonimmunoassay Test) Studies. Israel Journal of Veterinary Medicine. 1999;54:73-77.

62. Okewole EA. Seroprevalence of antibodies to Encephalitozoon cuniculi in domestic rabbits in Nigeria. Onderstepoort J Vet Res. 2008;75(1): 33-38.

63. Ashmawy KI, Abuakkada SS, Awad AM. Seroprevalence of antibodies to Encephalitozoon cuniculi and Toxoplasma gondii in farmed domestic rabbits in Egypt. Zoonoses Public Health. 2011;58(5):357-364.

64. Cox JC, Pye D, Edmonds JW, Shepherd R. An investigation of Encephalitozoon cuniculi in the wild rabbit Oryctolagus cuniculus in Victoria, Australia. J Hyg (Lond). 1980;84(2):295-300.

65. Cray C, Arcia G, Schneider R, Kelleher SA, Arheart KL. Evaluation of the usefulness of an ELISA and protein electrophoresis in the diagnosis of Encephalitozoon cuniculi infection in rabbits. Am J Vet Res. 2009; 70(4):478-482.

\section{Dovepress}

\section{Publish your work in this journal}

Veterinary Medicine: Research and Reports is an international, peer-reviewed, open access journal publishing original research, case reports, editorials, reviews and commentaries on all areas of veterinary medicine. The manuscript management system is completely online and includes a very quick and fair peer-review system.
Visit http://www.dovepress.com/testimonials.php to read real quotes from published authors. 